\title{
La Realidad Moral de los Derechos Humanos*
}

Este artículo se encuentra disponible en www.anuariocdh.uchile.cl

John Tasioulas ${ }^{* *}$

\section{Introducción}

$\angle$ a reciente elevación del discurso de derechos humanos a la categoría de lingua franca ética ha contribuido a una desordenada proliferación de demandas de derechos incompatibles e incluso frecuentemente inverosímiles. Para evitar que los derechos humanos sean víctimas de su propia popularidad, se requiere de una forma, organizada conforme a principios, para distinguir a los derechos verdaderos de la supuesta avalancha de derechos falsos. No es adecuado responder a dicha situación apelando a "los derechos humanos" proclamados en tratados y declaraciones internacionales. En primer lugar, carecen del carácter universal necesario: los instrumentos en que se establecen tales derechos suelen no ser vinculantes en términos legales y, los que sí lo son, no han sido suscritos por todas las naciones o bien han sido suscritos en muchos casos con reservas radicales. No obstante, es más importante el hecho de que el régimen internacional de derechos humanos no se autovalida en términos morales sino que su legitimidad depende de su concordancia con normas morales independientes. De este modo, el atajo que se busca mediante fundamentaciones legales y prácticas políticas nos lleva rápidamente de regreso al problema original. Aunque no hay concordancia entre los filósofos respecto de si el problema tiene solución y sobre cuál sería ésta, muchos están de acuerdo en la naturaleza general de cualquier solución adecuada. Según esta perspectiva estándar -como la he denominado- determinar cuáles derechos humanos existen remite a una cuestión moral que debe diferenciarse de la cuestión predominantemente institucional relativa a la medida en que se los reconoce, respeta, y observa. Thomas Nagel propone una formulación tajante de este punto de vista:

La existencia de derechos morales no depende de su reconocimiento político ni de su observancia sino, más bien, de la cuestión moral de si existe una justificación decisiva que permita incluir estas formas de inviolabilidad en la situación de cada miembro de la comunidad moral. La realidad de los derechos morales es puramente normativa antes que institucional -aunque, evidentemente, se puedan crear instituciones con el objeto de garantizar su cumplimiento- (Nagel 2002: 33) ${ }^{1}$.

\footnotetext{
* Título original: "The Moral Reality of Human Rights", incluido como capítulo en Freedom from Poverty as a Human Right. Who Owes What to the Very Poor?, Pogge, Thomas (Ed.), Organización de las Naciones Unidas para la Educación, la Ciencia y la Cultura (UNESCO), Oxford University Press, 2007, pp. 75-101. El presente capítulo se reproduce con la autorización expresa de UNESCO y del propio autor. Fue traducido del inglés por Jennifer Ann Metcalfe y revisado y editado por José Zalaquett y Mariano Fernández Valle. C UNESCO 2007.

** Deseo agradecer a James Griffin y a quienes asistieron a los seminarios sobre derechos humanos que impartimos en forma conjunta en la Universidad de Oxford durante el período académico de Trinity en el año 2003, por sus comentarios al primer borrador de este capítulo. Asimismo, fue provechoso presentar diferentes versiones de este trabajo en la Universidad de Melbourne, la Universidad Nacional de Australia y la Universidad Monash durante mi estadía a principios del año 2004, gracias a la Australian Bicentennial Fellowship. Tengo una deuda especial de gratitud con Onora O'Neill y Thomas Pogge por sus comentarios. También deseo agradecer a Jerry Cohen, Samantha Besson, James Nickel, Leif Wenar, Charles Beitz, Mark Philp y William Twining, por sus amables y útiles respuestas a versiones previas.

1 En Feinberg (2003) también se desarrolla y defiende exhaustivamente la perspectiva estándar.
} 
Los derechos humanos, concebidos de este modo, producen consecuencias en la creación, modificación o eliminación de instituciones, pero su existencia está determinada por el razonamiento moral y no por cualquier hecho institucional que eventualmente se presente. Evidentemente, los mecanismos institucionales -tales como los tratados, las declaraciones de derechos, los tribunales constitucionales, etcétera- pueden desempeñar un papel fundamental en la implementación de los derechos humanos. En concreto, pueden especificar el contenido de normas de derechos humanos más claramente en la medida en que adopten una determinada línea de interpretación o una determinada precisión normativa de entre varias posibles. Sin embargo, conforme a la perspectiva estándar, los derechos deben tener determinado un contenido mínimo aceptable, independientemente de cualquier especificación institucional posterior que se les asigne. En caso contrario, no se justificaría considerarlos como derechos humanos en primer lugar.

La distinción entre cuestiones normativas e institucionales no proviene simplemente-como pareciera implicar Nagel al no establecer diferencia alguna entre los "derechos morales" y los "derechos humanos"- del hecho de que los derechos humanos tienen justificación moral. Tampoco puede decirse que su carácter es el resultado de su alcance universal. Estas dos características distinguen a los derechos humanos de los derechos que dependen de instituciones y que no se justifican moralmente ni son poseídos por todos, como por ejemplo, los derechos legales de los propietarios de esclavos. Pero su posición moral no los hace diferentes de los derechos morales cuya existencia depende parcialmente de hechos institucionales, como por ejemplo, los derechos morales que emanan de la pertenencia a un esquema institucional, como una universidad o una nación. Asimismo, los derechos morales dependientes de la institucionalidad también pueden abarcar a toda la humanidad. Imaginemos, por ejemplo, un régimen económico global que le asigne a cada persona en el mundo el derecho a tener acceso a un recurso natural recién descubierto. Los derechos otorgados por un régimen de esta naturaleza, si bien tienen alcance universal y se justifican moralmente, no calificarían como derechos humanos en la perspectiva estándar. Más bien, lo que subyace a dicha perspectiva es la idea de que todos tienen el derecho moral de tener derechos humanos simplemente por el hecho de ser seres humanos. Esta definición parece implicar que no es necesario tomar en cuenta las relaciones especiales que existen entre personas, grupos e instituciones para determinar cuáles derechos humanos existen. Y esto es así, aunque la capacidad humana para establecer este tipo de relaciones sea una consideración pertinente para la identificación de los derechos humanos.

Este último punto destaca el hecho de que hay diferentes versiones de la "perspectiva estándar". Una versión más bien estricta interpreta los derechos humanos como "derechos naturales", es decir, derechos significativamente aptos para ser poseídos en el estado natural. Esta interpretación garantiza la naturaleza atemporal de los derechos humanos -se pueden asignar a todos los seres humanos a lo largo de la historia- pero solamente a costa, aparentemente, de excluir aquellos derechos que requieren o presuponen la existencia de prácticas sociales e instituciones no universales, como por ejemplo el derecho a la participación política o a un juicio justo. Por contraste, he señalado que los derechos humanos gozan de una universalidad temporalmente limitada, de modo que la cuestión de cuáles derechos humanos existen sólo puede responderse si se considera un contexto histórico específico. Para la gente -en la actualidad y en el futuro previsible- los derechos humanos son aquellos que se poseen por el hecho de ser una persona humana que vive en un mundo social sujeto a las condiciones de la modernidad (Tasioulas 2002a: 86-8 $)^{2}$. Esta limitación histórica permite que hechos sumamente generales acerca del diseño

2 Qué implica la modernidad, en este sentido, es una pregunta enorme. Para los fines que nos ocupan, simplemente respaldaré la caracterización que hace Charles Taylor al decir que constituye "aquella amalgama histórica sin precedentes de nuevas prácticas y formas institucionales (ciencia, tecnología, producción industrial y urbanización), de nuevas formas de vivir (individualismo, secularización y racionalidad instrumental) y de nuevas formas de malestar (enajenación, falta de sentido y una sensación de disolución social inminente)". (Taylor 2004: 1). 
institucional viable en el mundo moderno -como por ejemplo las formas de regulación legal, la participación política y la organización económica- desempeñen un papel en la determinación de cuáles derechos humanos reconocemos. Pero esto no es lo mismo que hacer depender la existencia de los derechos humanos de las disposiciones institucionales específicas que rigen en un momento y lugar determinados.

La perspectiva estándar, si se puede reivindicar, dota a los derechos humanos de gran poder crítico, lo que constituye un importante atractivo de esta visión. Entendidos de esta manera, los derechos humanos no son un reflejo pasivo del estado lamentable de un mundo en el que habitualmente se somete a millones de personas a torturas, a persecuciones por sus creencias religiosas o a la privación de los recursos materiales necesarios para una vida mínimamente digna. En cambio, así entendidos, fijan estándares a los cuales debe adaptarse la realidad. En vista de este poder crítico y de la resonancia generalizada del lenguaje de los derechos humanos, no sorprende que la estrategia de la UNESCO para erradicar la pobreza mundial se articule dentro de un "marco de derechos humanos". ¿Puede existir alguna manera más inequívoca de condenar la extrema pobreza que mediante la afirmación de que es un derecho humano no ser víctima de ella y, orientados e inspirados por esa afirmación, luchar por lograr ese derecho en un mundo en el cual 1,2 mil millones de personas sobreviven con menos de un dólar por día y un tercio de todas las muertes que ocurren cada año se deben a la pobreza? (Pogge, en este volumen ${ }^{3}$ ).

Evidentemente, una cosa es afirmar la existencia de un derecho a estar libre de situaciones de pobreza extrema $\left(\mathrm{HRP}^{4}\right)$ y otra muy distinta es lograr que dicha afirmación se cumpla. Permítanme ofrecer una breve y sumamente esquemática explicación de cómo se podría justificar un HRP dentro de una teoría amplia de los derechos "basados en intereses" ${ }^{5}$. En esta descripción, un derecho existe si el interés aislado de una persona tiene la importancia necesaria para justificar que se imponga a las demás el deber de respetar, proteger y promover dicho interés. Todos los seres humanos poseen derechos humanos por el solo hecho de ser humanos; en la explicación de los derechos basados en intereses, sólo los que se fundamentan en intereses universales poseen una importancia que justifica la generación de deberes en los demás. Si bien sería gratamente simétrico, no hay implicación alguna de que los deberes también deben ser universales (es decir, que todas las personas deben asumir los deberes correlativos a los derechos humanos que todas disfrutan). Algunas teorías del interés limitan o acotan aún más el carácter de los intereses que fundamentan los derechos humanos. James Griffin, por ejemplo, intenta demostrar que los derechos humanos provienen exclusivamente de los valores emanados de la condición de ser persona, específicamente, la autonomía y la libertad, otorgándole de esta manera un sentido determinado a la idea de que los derechos humanos son la protección de una condición especial: "la dignidad humana".

Al igual que Martha Nussbaum, prefiero una concepción más pluralista de los intereses que dan origen a los derechos humanos. Sin embargo, a diferencia de ella, me resisto a la idea de que es mejor visualizar estos valores como políticos en cuanto a su condición, de una manera que pre-

3 Nota de los editores: el autor se refiere al capítulo de Thomas Pogge "Severe Poverty as a Human Rights Violation", incluido en Freedom from Poverty as a Human Right. Who Owes What to the Very Poor?, Pogge, Thomas (Ed.), op. cit.

4 Nota de los editores: la sigla "HRP" es utilizada en el texto original para referir al término "human right to be free from severe poverty". Se ha mantenido esta sigla en la presente traducción.

5 Una exposición clásica de esta teoría aparece en Raz (1986: Cap. 7). Nótese, sin embargo, que debido a una interpretación "atemporal" de la universalidad, del tipo que señalé que debía rechazarse, Raz se muestra escéptico acerca de la existencia de los derechos humanos (o, al menos, del tipo de derechos que habitualmente se consideran derechos humanos). Ver Tasioulas (2002a: 86-8). 
tende desvincularse de los temas conflictivos sobre su explicación filosófica ${ }^{6}$. Ahora bien, incluso en la perspectiva basada en intereses, como la descrita hasta aquí, existen diferentes estrategias potenciales para justificar un HRP. Una de las estrategias es esencialmente derivativa. Empieza por justificar otros derechos determinados, por ejemplo el derecho a la participación política, para luego sostener que es necesario contar con un HRP, ya sea en términos instrumentales o constitutivos, para garantizar dichos derechos. Pero también se puede encontrar una justificación independiente de un HRP, que no provenga del interés por ejercer algún otro derecho sino de una defensa respecto de la cual las justificaciones derivativas sean complementarias. En términos generales, esta justificación independiente afirmaría lo siguiente:

(1) Para todos los seres humanos, la pobreza consiste en un grado significativo de carencias materiales que representan una grave amenaza para varios intereses: la salud, la seguridad física, la autonomía, la convivencia, la amistad, etcétera.

(2) En el caso de cada ser humano, la amenaza que implica la extrema pobreza para los intereses señalados en el inciso (1) es pro tanto de una gravedad tal como para justificar la imposición de deberes a los demás, como por ejemplo el de abstenerse de empobrecerlos, protegerlos del empobrecimiento y ayudar a aquellos que ya padecen de carencias materiales extremas.

(3) Los deberes generados -señalados en el inciso (2)- representan demandas viables respecto de los demás, tomando en cuenta las limitaciones creadas por las condiciones generales y relativamente afianzadas de la naturaleza humana y de la vida social en el mundo moderno.

Por lo tanto:

(4) Cada ser humano individual tiene derecho a no padecer la pobreza extrema.

El objetivo del HRP es garantizar el acceso de todas las personas a los medios de subsistencia -aire y agua limpia, alimentos, vestimenta y abrigo adecuados y un mínimo básico de atención médica- que permitan contar con lo necesario para tener una "oportunidad razonable de llevar una vida medianamente saludable y activa de una duración relativamente normal, salvo por la acción de eventos trágicos" (Shue 1996a: 23). Nada de lo señalado en el anterior argumento impide la existencia de un derecho humano que se haga extensivo a recursos y oportunidades adicionales a los necesarios para proteger a las personas contra la pobreza extrema. Es discutible, por ejemplo, que el artículo 25(1) de la Declaración Universal de los Derechos Humanos (DUDH) -que hace referencia al derecho de toda persona a un nivel de vida adecuado que garantice su bienestar personal y no sólo la mera subsistencia- consagre un derecho económico más elevado que el HRP, al menos si aceptamos la medida empírica ortodoxa de la pobreza extrema fijada en el umbral de un dólar (estadounidense) diario ${ }^{7}$.

6 Para la visión de Griffin y mi crítica de ésta, ver Griffin (2001b) y Tasioulas (2002a). Para la visión de Nussbaum y mi escepticismo acerca de la interpretación política de los derechos humanos al estilo de Rawls, ver Nussbaum (2000: Cap. 2) y Tasioulas (2002b: 390-5).

7 Toda persona tiene derecho a un nivel de vida adecuado que le asegure, así como a su familia, la salud y el bienestar, y en especial la alimentación, el vestido, la vivienda, la asistencia médica y los servicios sociales necesarios; tiene asimismo derecho a los seguros en caso de desempleo, enfermedad, invalidez, viudez, vejez u otros casos de pérdida de sus medios de subsistencia por circunstancias independientes de su voluntad. Ver también el artículo 11(1) del Pacto Internacional sobre Derechos Económicos, Sociales y Culturales. 


\section{II. ¿Un simple derecho "retórico"8?}

En este capítulo hago una defensa del HRP frente a una línea de ataque que se opone a la separación que la perspectiva estándar hace entre lo normativo y lo institucional en lo que se refiere a la identificación de los derechos humanos (o, en el caso de la segunda objeción -que se indica más adelante-, respecto de los denominados derechos "de bienestar", como el HRP). Por supuesto, en general el escepticismo acerca de los derechos humanos está fuertemente determinado. Una de las fuentes de dicho escepticismo es un rechazo rotundo de al menos algunos de los "valores" que los derechos humanos encarnan, caracterizándolos como viciados o, quizás, ni siquiera como valores. Esto está ejemplificado por la habitual crítica del inventario tradicional de los derechos humanos como algo que refleja una limitada perspectiva individualista o masculina que se contrapone fuertemente a los así llamados valores "comunitarios" o "femeninos" de la armonía social y el cuidado. Otro tipo de escepticismo cuestiona ya no los valores que subyacen a los derechos humanos sino su utilización como "prueba de fuego" de la legitimidad de todas las comunidades políticas sin excepción, incluso aquellas cuyas tradiciones simbolizan orientaciones éticas muy diferentes. Con independencia de su respectivo marco conceptual, ambas formas de escepticismo no parecen plausibles si se las enfrenta con la existencia misma de un HRP, puesto que evidentemente éste no refleja preocupaciones que sean ni claramente individualistas ni occidentales.

Pero una tercera forma de escepticismo plantea una amenaza mayor. Se trata de la afirmación generalizada de que, en el estado actual y previsible del mundo, la afirmación de un HRP es un gesto irremediablemente utópico. Por lo tanto, no tiene razón de ser en una realidad normativa que, al fin y al cabo, debe informarnos sobre cuáles son nuestros derechos y sobre quiénes están obligados por ellos. Permitirse este tipo de gestos equivale a los inofensivos conjuros de la "magia blanca" (Geuss 2001a: 144) o, peor aún, a una "burla cruel para los pobres y necesitados" (O'Neill 1996: 133). Estos gestos también son potencialmente contraproducentes en la medida que fomentan expectativas poco realistas entre los inevitablemente frustrados activistas y potenciales beneficiarios. Alternativamente, si proclamar la existencia de un HRP tiene algún valor, es que los pronunciamientos retóricos pueden lograr, a pesar de su falsedad, el expresivo valor de manifestar buena fe o el valor estratégico de realizar modificaciones deseables en el comportamiento individual e institucional, por ejemplo. Pero estos pronunciamientos no afirman ninguna verdad normativa: el 'derecho' en cuestión es solamente una aspiración política o "derecho retórico", y no un derecho bona fide de todos los individuos.

Mi preocupación se centra en dos formas específicas que adopta esta forma de escepticismo cuando se ve enfrentada a un HRP. Según la objeción relativa a la ejecutabilidad ${ }^{9}$, los derechos efectivamente son demandas ejecutables que las personas pueden reclamar en contra de aqueIlos que asumen las obligaciones correlativas: forzarlos a cumplir con sus obligaciones o, por lo menos, a proporcionar una reparación efectiva por el hecho de no hacerlo. Un requisito para la existencia de un derecho es que realmente sea ejecutable ahora y no una vez que el mundo esté en mejores condiciones. Como señala Raymond Geuss, es "consustancial a la existencia de una serie de (derechos) que exista algún mecanismo determinable y medianamente eficaz para lograr su cumplimiento". (Geuss 2001a: 143).

En consecuencia, los derechos humanos serían derechos que poseen todos los seres humanos, cuyo cumplimiento puede exigirse a los responsables pertinentes, garantizando de este modo el acceso seguro al objeto de sus derechos o, en su defecto, a una compensación adecuada. En la

8 Nota de los editores: A "Manifesto" Right en la versión original.

9 Nota de los editores: "Enforceability objection" en la versión original. 
práctica, sin embargo, existen muy pocos derechos ejecutables en términos globales en el mundo actual, si es que los hay. En efecto, Geuss incluso llega a afirmar que su objeción es "fatal para la idea misma de un derecho natural o derecho humano", señalando que es "intrínsecamente confusa" (Geuss 2001a: 146, 156). Para Geuss, afirmar un HRP equivale a confundir la existencia de un derecho con la simple creencia moral de lo que sería una situación altamente apreciable. Evidentemente, al final podríamos llegar a establecer un sistema de demandas ejecutables que beneficie a todos los seres humanos, por ejemplo mediante la creación de un régimen internacional eficaz de derechos humanos. Pero tales derechos existirán porque los hemos convertido en demandas ejecutables; su existencia como derechos legales efectivos no será previa a la posibilidad de su realización institucional. Esto es así porque "la única cosa que puede servir para dicho propósito pareciera ser la luz vacilante de nuestras variables creencias morales" (Geuss 2001a: 144), no algo que merece ser descrito como "derechos".

Según la segunda objeción relativa a la demandabilidad ${ }^{10}$ de los derechos, éstos son intrínsecamente demandables, aunque no siempre sean ejecutables. Esto significa que deben existir agentes determinables frente a quienes reclamar un derecho, agentes que poseen las obligaciones que son la contraparte de dichos derechos. Al parecer, algunos derechos humanos cumplen con esta limitación sin mayores problemas, por ejemplo las clásicas libertades "negativas", como el derecho a no ser sometido a tortura. La principal implicación normativa de este derecho es que impone a todos el deber de abstenerse de la tortura. No obstante, habitualmente se piensa que el derecho a estar libre de situaciones de pobreza extrema implica deberes positivos en cuanto a proporcionar oportunidades y recursos a sus titulares. Evidentemente, no se estima que estos deberes incumben a todos los seres humanos. Como señala Onora O'Neill: "el derecho a que a uno no lo maten o a hablar libremente está equiparado por obligaciones globales de no matar ni obstaculizar la libertad de expresión, pero el derecho universal a la alimentación no se puede equiparar con una obligación global de proporcionar una pequeña porción alícuota de alimentos" (O'Neill 2000: 135). En cambio, tales derechos requieren de algún tipo de estructura institucional para asignar los deberes y definir su contenido. Ante la falta de deberes asignados y definidos institucionalmente, la afirmación de un HRP es, nuevamente, una cuestión retórica que tiene consecuencias políticas potencialmente dañinas. En su reemplazo, O'Neill estaría a favor del reconocimiento de obligaciones imperfectas -es decir, obligaciones sin derechos morales correlativos- con el fin de socorrer a aquellos en situación de extrema necesidad y, en los casos pertinentes, ayudar a construir sistemas institucionales de derechos de asistencia social. Pero tales derechos de asistencia social, que dependen de que las instituciones asignen los deberes correlativos, no van a ser derechos humanos como se entienden en la perspectiva habitual. Serán, en cambio, derechos institucionales que permiten la manifestación de obligaciones imperfectas que no son, por una cuestión de razonamiento puramente moral, la contraparte de los derechos individuales ${ }^{11}$.

Ambas objeciones recién analizadas deben distinguirse de la crítica más profunda del HRP como algo "utópico". Esta afirmación sostiene que no es factible lograr un mundo en el cual se garantice ese derecho a todos los seres humanos, tomando en consideración hechos sumamente generales e inerradicables acerca de las capacidades humanas y la motivación, la escasez de recursos y las limitaciones inexorables de la vida en sociedad. Esta violación de la máxima de que el "deber"

10 Nota de los editores: "Claimability objection" en la versión original.

11 El resultado del análisis de O’Neill es que el deber de aliviar la pobreza extrema es el deber imperfecto de la caridad, en lugar del deber perfecto de la justicia. Ver O’Neill (1989: 225). Este hecho tiene varias consecuencias para su teoría, siendo la más importante que el incumplimiento de los deberes imperfectos no agravia directamente a otra persona. Por ello, dichos deberes carecen de la rigurosidad de los deberes de la justicia (aquellos que conllevan derechos correlativos), que efectivamente prohíben el mal en contra de otros seres determinables. 
implica el hecho de "poder", lo descalifica como derecho genuino de todos los seres humanos. Especulando en este sentido, en una conferencia dictada en la UNESCO, Richard Rorty observó la desalentadora perspectiva de que "los ricos del mundo pueden encontrarse en la situación de que alguien proponga compartir su única hogaza de pan con cien personas famélicas. Aunque la comparta, todos, incluido quien comparte, pasarán hambre de cualquier manera. Por esto, esa persona fácilmente puede ser culpable (...) ya sea de autoengaño o de hipocresía" (Rorty 1996; ver, también Geuss 2001b: 101-3). Ahora bien, un defensor del HRP puede responder a esta objeción de varias maneras: argumentando que demuestra un pesimismo injustificado acerca de los medios disponibles para garantizar ese derecho ${ }^{12}$; mediante una relativización de lo que el HRP exige en materia de medios ${ }^{13}$; o insistiendo en que la factibilidad debe ser evaluada respecto del derecho individual en cada caso particular y no por el conjunto de todas las exigencias de derechos ${ }^{14}$. Cualquiera sea la respuesta que se adopte, el punto clave en este caso es que el defensor de la teoría basada en los intereses deberá aceptar que debe satisfacerse una limitación de la factibilidad como preludio a la afirmación del HRP. Su pertinencia se señaló en el paso (3) del argumento esquemático esbozado en la Sección I. El reconocimiento de su importancia es también la motivación de mi sugerencia de que la existencia de los derechos humanos se debe determinar dentro de un contexto histórico específico, en vista de que el contexto es lo que permitirá llegar a juicios suficientemente confiables acerca de la factibilidad. Todo lo anterior difiere de la respuesta apropiada a las objeciones de ejecutabilidad y demandabilidad que invocan reclamos que pueden no ser satisfechos incluso cuando se ha cumplido con la limitación de la factibilidad. Yo sostengo que, ni la ejecutabilidad ni la demandabilidad son condiciones de existencia de los derechos humanos.

Nótese, asimismo, que si bien difieren considerablemente en cuanto al grado de oposición a la perspectiva estándar de los derechos humanos, tanto las objeciones basadas la ejecutabilidad como en la demandabilidad de los derechos cuestionan la brecha normativa e institucional que está implícita en la mencionada perspectiva estándar. Evidentemente, no hay ninguna conexión necesaria entre la ejecutabilidad y la demandabilidad de los derechos, por una parte, y los mecanismos institucionales que los garantizan, por la otra. Pero a falta de intervención divina o de una naturaleza reencantada, la ejecutabilidad evidentemente se logra a través de mecanismos institucionales eficaces (como también mediante varios otros factores culturales más amplios y cualidades personales que garantizan el buen funcionamiento de tales mecanismos ${ }^{15}$ ). Del mismo modo, la demandabilidad no necesariamente requiere de la existencia de instituciones que asignen los deberes pertinentes -se supone que eso debía ser ilustrado por el ejemplo de las obligaciones universales negativas, tales como el deber de abstenerse de la tortura, que da origen al derecho de no ser torturado-. Pero en el caso de derechos que fundamentan deberes que requieren del otorgamiento activo de oportunidades, recursos, etcétera, se necesita de una especificación institucional respecto de los responsables pertinentes para poder cumplir con la condición de demandabilidad.

\footnotetext{
12 Tanto Thomas Pogge como Peter Singer han sugerido que el costo de la erradicación de la pobreza más extrema en todo el mundo es cercano al $1 \%$ del ingreso anual disponible del decil más rico de la humanidad. Ver Pogge (2002b: 152) y Singer (2002: 194).

13 Por ejemplo, Pogge (2002a: 68), quien sugiere que no se puede tener derecho a recursos que otros necesitan para poder sobrevivir.

14 Ver en este sentido, Waldron (1993b: 207-8).

15 Ver, entre otros, James (2003) y Pogge (2002a: 62-3).
} 


\section{Respuesta a la objeción relativa a la ejecutabilidad}

El argumento acerca de la ejecutabilidad que esgrime Geuss depende del contraste entre una demanda ejecutable (un derecho genuino) y una creencia moral, incluyendo la creencia moral sobre cuáles "demandas ejecutables" debieran existir. La perspectiva estándar de los derechos humanos, sostiene Geuss, ofrece solamente esto último, engañándonos con "una especie de bombo" (Geuss 2001a: 144). Pero ¿por qué el que las demandas sobre la existencia de los derechos expresen creencias sobre los derechos inherentes a todos los seres humanos -sin considerar si son ejecutables actualmente- habría de convertirlos en gestos retóricos ante la falta de un mecanismo confiable para darles fuerza?

La respuesta de Geuss tiene dos aspectos: primero que hay un desacuerdo radical en asuntos morales y segundo, que aún si este disminuye no sería una "garantía de acción eficaz" (Geuss 2001a: 146). Sin embargo, el segundo aspecto simplemente es una reiteración de su tesis mientras que el primero hace una generalización que va mucho más allá del discurso sobre los derechos, puesto que no es menos intensa la controversia sobre los deberes de las personas, sus "verdaderos" intereses, los ideales que merecen ser adoptados, etcétera. En consecuencia, ¿se desprende de lo anterior que, a falta de consenso, estas ideas también son ilusorias? En ese caso, el argumento de Geuss queda desenmascarado como un ataque acérrimo contra el pensamiento moral. Es más, es un ataque que vulnera su propia tesis sobre la ejecutabilidad, en la medida que ésta también es parcialmente producto de un argumento moral polémico. En todo caso, ¿por qué habría de tener consecuencias tan drásticas un desacuerdo moral sumamente profundo e interminable? Evidentemente, la respuesta es que Geuss piensa que es la base para rechazar cualquier forma de objetividad ética: el dominio de las creencias morales es uno de simple creencia y, por lo tanto, uno de desacuerdo sin solución racional. Como partidario de una perspectiva claramente nietzscheana, no sólo repudia la objetividad ética sino que, además, probablemente interpretaría cualquier aspiración en ese sentido como muestra del resentimiento de quien reclama un derecho hacia el supuesto responsable. Desde este punto de vista desprestigiante, las exigencias de objetividad son intentos de los débiles por invocar algún tipo de "fuerza" coercitiva imaginaria que respalde sus demandas de protección ${ }^{16}$. Pero el partidario de los derechos humanos, que crea que éstos tienen una base objetiva, no aceptará estas movidas nietzscheanas. Insistirá, en cambio, en que hay buenas razones para desvincular la aspiración a la objetividad de cualquier afirmación sobre el poder, o lo que Rorty denomina un "aliado poderoso y no contingente" que hará valer las creencias de uno frente a los transgresores. Y con la posibilidad de la justificación objetiva en juego: ¿por qué no habríamos de entender el concepto de los derechos como derechos genuinos que permiten aferrarse firmemente de la realidad social, aun cuando no sean ejecutables en algún momento dado para la gran mayoría de la gente?

No obstante, podríamos interpretar la perspectiva de Geuss como algo menos que una negación radical de la objetividad ética. La razón por la cual las aserciones de los derechos humanos constituyen "simples creencias" a falta de un mecanismo que garantice su observancia, está constituida por la idea de que los esfuerzos por justificar objetivamente los derechos humanos en particular no tienen destino. Geuss sencillamente presupone que esto es así en History and Illusion in Politics, pero en fechas más recientes insinuó el incipiente argumento que se expone a continuación:

16 Richard Rorty planteó precisamente este punto en relación con los Derechos Humanos en la conferencia organizada por Amnistía Internacional que dictó en Oxford (Oxford Amnesty Lecture): "La idea de que tendremos que esperar que los fuertes fijen sus ojitos porcinos en el sufrimiento de los débiles nos produce resentimiento. Si no lo hacen, tenemos la intensa esperanza de que exista algo más poderoso y más fuerte que los dañe -si no es un Dios vengativo, que sea el alzamiento de un proletariado vengativo o, al menos, un superego vengativo o, como mínimo, la majestuosidad ofendida del tribunal de Kant de la razón práctica pura" (1993: 130-1). 
[L]o que en ocasiones se denomina como las "bases normativas" de esta teoría ["los derechos humanos naturales"] no es para nada claro (ni convincente). Inmediatamente surge la sospecha de que la razón subyacente es que el proyecto de encontrar una "fundamentación" totalmente secular, inmanente para tal teoría, es incoherente: simplemente no hay una trayectoria argumentativa directa que conduzca desde los hechos de la naturaleza y la psicología humana -tal y como los conocemos a través de la experiencia y las formas habituales de investigación científica, los requisitos económicos y comerciales del tipo de sociedad en la que vivimos y algunos principios mínimos de racionalidad- hacia la doctrina deseada de los derechos humanos naturales. (2003: 47)

Lo anterior plantea dos problemas. El primero es que el tipo de justificación que Geuss considera cuestionable no es el que sería planteado por alguien que cree en los derechos humanos con fundamento objetivo. El concepto de "lo humano" o de los "intereses humanos" que forma la base de una teoría convincente de los derechos humanos no debería ser interpretado de manera neutral en términos valóricos ni tampoco como algo dependiente de una explicación "liviana" del propio interés racional. Esta ambiciosa caracterización de lo que sería necesario para justificar los derechos humanos podrá calzar con algunas teorías, particularmente aquellas de índole contractualista, pero no coincide con la autocomprensión de los principales defensores contemporáneos del enfoque de los derechos humanos basado en los intereses ${ }^{17}$. Geuss necesita justificar mucho más su "sospecha" sobre el proyecto de derechos humanos para debilitar dicha posición. El segundo problema es que Geuss transita con demasiada rapidez desde la afirmación de que los derechos humanos no tienen asidero en una realidad moral "objetiva" hacia la idea de que la única realidad que podrían lograr es la de convertirse en demandas ejecutables. Pero este punto sobre el estatus metaético no produce -automáticamente- ese beneficio normativo tan específico. Los partidarios antiobjetivistas de la perspectiva estándar probablemente insistirán en que, si bien los derechos humanos no son susceptibles de una justificación moral objetiva, su existencia no necesariamente tiene que ser tan brutalmente institucional. Podría basarse, en lugar de ello, en una subjetividad ética particularmente refinada, o bien en las implicancias de ciertas prácticas sociales a las cuales estamos ineludiblemente comprometidos.

¿Significa esto que podemos descartar la idea de que la ejecutabilidad tiene alguna relación interesante con las condiciones de existencia de los derechos humanos? Bueno, una conclusión a la que podríamos llegar es que sí la tiene, pero de un modo muy diferente al estipulado por Geuss. Se puede ver cómo va surgiendo el punto -en contra de sus propias intenciones- en el reciente intento de Susan James por ampliar la tesis central de Geuss a partir del desarrollo de las condiciones que convierten a los derechos en demandas ejecutables. Según James, una de estas condiciones es que los responsables sepan tanto lo que tienen obligación de hacer como también cómo deben hacerlo. Requisitos adicionales son la existencia de un ambiente social general en el cual ese derecho sea considerado valioso y el apoyo necesario para su cumplimiento mediante arreglos sociales adecuados (James 2003: 140, 143). Ahora bien, un defensor de la perspectiva estándar puede responder que una técnica importante para lograr que la gente satisfaga ambas condiciones consiste en permitirles que entiendan y actúen de manera concordante con la justificación moral de la imposición de ciertos deberes. Dicho de otro modo, la valoración de la posible existencia de un derecho como interés que justifica imponer deberes a los demás ayuda a generar el contexto más amplio de comprensión y respaldo necesario para que los derechos tengan un verdadero carácter ejecutable.

Sin embargo, todavía no hemos descartado la idea de la existencia de un vínculo conceptual entre los derechos y su ejecutabilidad. Aun cuando rechacemos la identificación intransigente de Geuss

17 Ver, por ejemplo, Griffin (2001a: 313) y Nussbaum (2000: Cap. 1). 
respecto de los derechos que tienen la fuerza para hacerse respetar, ¿no podríamos rescatar de su discusión la idea de que las demandas de derechos expresan la creencia moral de que ciertos derechos debieran obtenerse mediante algún mecanismo confiable de ejecución? En este sentido, el elemento institucional dentro de las condiciones de existencia de los derechos sería más bien normativo antes que un reflejo de la realidad social misma. Dicho de otra forma, los derechos sólo existirán si son derechos que se deben hacer respetar, independientemente de si realmente son ejecutables en la actualidad. Este tipo de propuesta plantea un problema inmediato, a saber, el carácter indeterminado del "mecanismo confiable de ejecución". Una forma frecuente de aumentar la definición de la frase anterior está representada por la tesis de Jürgen Habermas, que afirma que "los derechos humanos tienen un carácter intrínsecamente jurídico y conceptualmente están orientados hacia su realización por parte de órganos legislativos" (Habermas 2001: 122). Quienes adhieren a esta venerable línea de pensamiento defienden la posición de que "debiera haber una teoría legal" de derechos morales, como Joel Feinberg ha denominado adecuadamente. Según esta teoría, la afirmación "A tiene el derecho moral de hacer (tener o ser) X" debe entenderse como "A debiera tener un derecho legal respecto de X" (Feinberg 2003: 45) ${ }^{18}$.

Considero que, incluso esta tesis más débil debiera ser descartada. En primer lugar, no se condice con sus propios términos pues es un hecho ampliamente conocido que la realización legal de los derechos humanos no es condición suficiente para otorgar la autoridad legal necesaria para hacerlos cumplir, y menos el poder real que se requiere para hacerlo. Para comenzar, esto se debe a que un derecho legal puede existir sin estar asociado con un remedio -el derecho puede ser de índole declaratorio, por ejemplo, o ejecutable solamente por una persona o entidad diferente del titular del derecho, como sería algún organismo de gobierno ${ }^{19}$-. Si existe un derecho por ley es una cuestión diferente de si es justiciable o (legalmente) ejecutable. Indudablemente, esto es válido para amplias secciones del Derecho Internacional de los Derechos Humanos. Todavía más, aunque la ejecutabilidad de un derecho putativo esté legalmente autorizada, dicha autorización no supone que exista el poder de facto para hacer cumplir el derecho. En cambio, podría darse que el derecho sea, efectivamente, no ejecutable debido a deficiencias en las motivaciones y capacidades de los titulares del derecho y de los responsables pertinentes. Por ejemplo, los titulares pueden no conocer sus derechos o carecer de los medios para hacerlos valer, mientras que los responsables pueden no estar en condiciones o no estar dispuestos a identificar sus obligaciones o a cumplir con ellas. Por último, evidentemente, muchos supuestos derechos humanos son promulgados por gobiernos cínicos con fines cosméticos o estratégicos, sin tener la real intención de defenderlos.

No obstante, estas observaciones podrían sencillamente imponer una leve modificación de la tesis original, a saber, que afirmar que un derecho humano existe equivale a decir que debiera ser un derecho legal efectivamente ejecutable. Pero incluso con esta modificación siguen existiendo serios problemas. Como asunto conceptual, la tesis revisada no calza con el discurso habitual de los derechos morales. A menudo nos referimos a tales derechos en términos indicativos como algo que se ha ejercido o violado incluso antes de que se promulguen como ley. Típicamente, nos sentimos justificados a reafirmar su existencia sin tomar en consideración cuál es su situación

18 Vale la pena tener presente en este punto la advertencia de $\mathrm{O}^{\prime}$ Neill respecto de la adopción de cualquier "contraste supuestamente exhaustivo entre lo que la ley exige cumplir y aquello que es sencillamente voluntario". Ver $\mathrm{O}^{\prime} \mathrm{Neill}$ (1989: 232). Pueden existir otras versiones de la tesis de la ejecutabilidad que no estén específicamente vinculadas con la observancia legal. Pero surgirán preguntas en cuanto a si son plausibles y, en tal caso, suficientemente determinadas como para ser de interés.

19 A partir de la discusión de Geuss, no queda claro si los derechos deben ser ejecutables a discreción del titular del derecho, o bien si es suficiente que un tercero pueda hacerlos cumplir a nombre del titular del derecho. En lo que sigue, dejo de lado este tema. 
legal. Tomemos el caso de los esclavos en Estados Unidos en la época anterior a la abolición de la esclavitud. Se considera, naturalmente, que los esclavos tenían derechos que fueron violados. Afirmar que los esclavos tenían estos derechos no es lo mismo que aseverar cuáles derechos de libertad les debiera haber otorgado la ley, si bien puede operar como una premisa en un argumento a favor de esto último. En respuesta, la tesis legal podría presentarse ahora como una interpretación revisionista que busca infundir el rigor que tanto requiere el habitual discurso sobre los derechos humanos. Pero, aun si admitimos las graves imperfecciones de dicho discurso, la tesis legal no proporciona el remedio necesario. En cambio, se ve derrotada por una serie de objeciones sustantivas.

Una de las impugnaciones es que la propuesta de consagrar un derecho humano en la ley puede estar en conflicto con otras consideraciones y verse superada por ellas (incluidas aquellas fundamentadas en la preocupación por los derechos humanos). Por ejemplo, considerando todos los factores en juego, un gobierno haría bien en no promulgar el derecho al aborto en un país firmemente católico si con ello causara una grave alteración social y una fuerte disminución de la confianza de la gente en el sistema jurídico. Esto nos lleva a un punto adicional: aun cuando establecer por ley un derecho específico no tenga un costo social demasiado elevado, parece exagerado afirmar que ello es siempre necesario para que la comunidad logre gozar de tal derecho. El HRP podría ejecutarse efectivamente en una sociedad dada gracias a la influencia conjunta de políticas democráticas, una economía que funciona bien, fuertes lazos familiares y un carácter social firmemente arraigado de respeto por el derecho en cuestión, sin que necesariamente éste se consagre en la ley. Además, como demuestra este último ejemplo, incluso en los casos en que se requieren derechos legales de algún tipo para garantizar el cumplimiento de un derecho humano, los derechos legales no necesitan tener el mismo contenido que el derecho humano (Pogge 2002a: 46).

Sin embargo, quizás algunos defensores de la tesis legal están pensando en la afirmación más débil de que siempre existe una razón pro tanto para transformar un derecho humano en un derecho legal efectivamente ejecutable. Pero incluso esta tesis más débil es discutible, particularmente si se interpreta como una limitación conceptual a la idea misma del derecho humano. La propia naturaleza de algunos derechos humanos pareciera ser tal que hace que sea inadecuado o inútil reconocer razón alguna -y ciertamente ninguna razón que equivalga a una obligación pro tanto- a favor de su promulgación legal. Por ejemplo, existen buenos motivos, vinculados con el respeto de la privacidad, para no admitir razón que permita reconocer un derecho a intervenir en decisiones familiares importantes o un derecho a la fidelidad marital, suponiendo que estos dos derechos son (implicaciones de) derechos humanos. No se trata de que las razones positivas para su consagración se vean contrarrestadas por consideraciones mayores sino que la misma naturaleza de los derechos va en contra de la razón de su establecimiento desde un principio. No obstante, este hecho por sí solo no debe dar origen a dudas acerca de su condición de derechos humanos. Nuevamente, en lo que se refiere a ciertos derechos humanos, su consagración para garantizar la ejecutabilidad no tiene mucho sentido porque éstos cubren situaciones en las que el propio sistema jurídico se ha convertido en la principal amenaza contra los derechos humanos. Un ejemplo de esto es el derecho a rebelarse en contra de un gobierno tiránico.

A la luz de los complicados temas que implica el establecimiento legal de los derechos humanos, podemos someter la tesis legal al siguiente experimento de pensamiento. Si lo único que supiéramos de un derecho no específico es que es un derecho humano genuino, ¿implicaría eso la existencia de una razón pro tanto (sin siquiera mencionar la obligación pro tanto) de promulgar legalmente dicho derecho sin tomar en consideración su contenido y las particulares circunstancias de la comunidad pertinente? Pienso que la discusión precedente nos proporciona bases sólidas para responder que "no". 
El punto de vista jurídico es tan solo una de las interpretaciones contemporáneas de los derechos humanos que incorpora a su naturaleza la preocupación por su cumplimiento. Otra interpretación de este tipo es la teoría propuesta por John Rawls y, es precisamente su carácter centrado en la ejecutabilidad lo que explica por qué su lista de derechos humanos es tan drásticamente minimalista (Rawls 1999b: 65) ${ }^{20}$. Esta teoría no contempla la libertad de expresión ni de reunión, como tampoco el derecho de participación política, la educación y la atención médica y el derecho de igualdad de libertad religiosa. Además, Rawls solamente respalda el derecho a la subsistencia (como una consecuencia del derecho a la vida), pero no un derecho exigente que garantice lo que se requiere para tener un nivel de vida digno o adecuado ${ }^{21}$. La forma en que Rawls concibe los derechos humanos los remite esencialmente a la moralidad política que gobierna las relaciones entre comunidades políticas. No obstante, es más importante que los considera como normas cuya violación, si es suficientemente amplia y duradera, da origen a una justificación -en principio- para una intervención potente por parte de personas liberales y decentes. En particular, en vista de la brevedad de su lista de derechos humanos y de cierta evidencia textual (ver Rawls 1999b: 94 n. 6), pareciera que los principios que para Rawls justificarían la intervención armada como respuesta a graves violaciones servirían también de criterio para identificar a "los derechos humanos propiamente tales". Supuestamente, el principal beneficio de la explicación de Rawls es que da a la noción de los derechos humanos un carácter algo más determinado, enfrentando así la persistente tendencia a invocarla prácticamente sin aludir a criterio alguno mientras simultáneamente se evade una respuesta a las acusaciones de etnocentrismo distinguiendo categóricamente entre los derechos ciudadanos en las democracias liberales, por una parte y los derechos humanos, por otra.

Sin embargo, en última instancia, la concepción revisionista que Rawls tiene de los derechos humanos no prospera. Su enfoque margina la percepción tradicional de que, ante todo, los derechos humanos protegen intereses humanos esenciales. En ese sentido, son uno de los aportes para la formación de principios en las relaciones entre Estados, incluida la intervención coercitiva, pero no tienen un vínculo conceptual con una forma particular para remediar su violación. Inevitablemente, la visión de Rawls produce un inventario de derechos humanos sumamente trunco, pero sólo porque fusiona las condiciones de existencia de éstos con otro tema diferente, a saber, las condiciones bajo las cuales se justifica -si eso es posible- la intervención de una sociedad en los asuntos de otra (Tasioulas 2002b: 384-90). Por otra parte, la supuesta ganancia lograda al evitar el etnocentrismo es fundamentalmente ilusoria. La doctrina de Rawls claramente nos impide calificar críticamente como violaciones a los "derechos humanos" a algunas prácticas que contradicen los derechos liberales (por ejemplo, la discriminación en razón del sexo o el hecho deliberado de no proporcionar a los miembros de una sociedad "Ios medios suficientes para llevar, en términos generales, (. . ) vidas razonables que valgan la pena" (Rawls 1999b: 114). Al mismo tiempo, una sociedad que discrimine en función del sexo o que deliberadamente no garantice un nivel de vida adecuado para todos sería caracterizada por Rawls -en el mejor de los casos- como "no completamente irrazonable", lo que supone que es aún defectuosa en términos de la justicia. No obstante, la justicia forma parte del campo de los derechos, por lo que la crítica contra cualquier sociedad de este tipo la condena por no respetar los derechos liberales. En otras palabras, se genera una forma extraña de duplicación: los derechos liberales forman parte de los

20 Una opinión similar se puede ver en Beitz (2004: 208): "Los derechos humanos constituyen normas en cuanto a la ley y las políticas públicas, cuya violación en una escala suficiente es una justificación pro tanto para las acciones internacionales de reparación".

21 Yo sostengo que la explicación de Rawls de los derechos humanos basada en la intervención conduce a un derecho a la subsistencia más que a las condiciones para una vida adecuada y que, a su vez, produce un deber de asistencia excesivamente débil en "sociedades afligidas". Ver Tasioulas (2005). 
principios de la justicia que se aplican universalmente (todas las sociedades deben respetarlos y, al no hacerlo, son sociedades injustas), pero los derechos humanos solamente son un subconjunto de estos derechos. Apropiarse de la frase "los derechos humanos" para referirse a un subconjunto de derechos liberales de aplicación universal no alcanza a desactivar el problema fundamental del etnocentrismo que afecta a la teoría más general de Rawls.

Ahora bien, hay quienes responderían que los problemas de Rawls se derivan parcialmente de haber vinculado los derechos humanos con la "intervención vigorosa" de una sociedad en contra de otra y que la solución consiste en adoptar una interpretación más amplia de esa idea, de modo que las protestas enérgicas manifestadas a través de canales diplomáticos puedan valer también como "intervenciones vigorosas". Una consecuencia evidente de tal propuesta sería una lista más extensa de derechos humanos que aquella propuesta por Rawls. Con todo, dejando de lado el persistente problema del etnocentrismo, uno podría preguntar en este momento si una versión tan atenuada de lo que constituye una "intervención vigorosa" cumple alguna función de peso en la teoría de los derechos humanos. Surge la tentación de afirmar que no lo hace. Sin embargo, al menos en un sentido, cumple demasiadas funciones. Esto queda demostrado por otro problema que afecta a la explicación de los derechos humanos basada en la intervención, inclusive en esta interpretación más amplia: vincula el concepto de los derechos humanos a un arreglo específico de orden geopolítico, compuesto por entidades que son claramente tipo Estado (pueblos). Una extraña consecuencia de esta visión es que nos impide plantear significativamente la cuestión de si se puede justificar la creación de un gobierno mundial con el fin de proteger los derechos humanos, en vista de que los derechos humanos deben ser entendidos -por su naturaleza- como aquello que regula las relaciones entre comunidades políticas diferenciadas, cuyos gobiernos afirman tener autoridad sobre territorios definidos. En vista de que la perspectiva basada en los intereses ofrece un criterio determinado para identificar los derechos humanos, uno en el que calzan adecuadamente muchas de las aspiraciones defendibles que intentan lograr los movimientos de derechos humanos, ¿por qué debiéramos dar un paso adicional y subordinar el concepto de derechos humanos a las características contingentes del orden político global?

Creo que debiéramos rechazar los análisis de corte legal e intervencionista sobre los derechos humanos. Del reconocimiento de un derecho humano no se puede inferir a priori ni siquiera la conclusión pro tanto de que debería ser establecido por ley o de que constituye la base para una intervención armada en casos de violación mayúscula. Se debe desarrollar un argumento para cada derecho a los efectos de justificar su consagración legal o una política de intervención ante su violación, sea en general o en cualquier caso particular; las imposiciones conceptuales no pueden reemplazar dicho argumento ni permiten suponer cuáles serán sus resultados. Esta conclusión confirma la idea de que los derechos ocupan una posición intermedia en nuestro pensamiento ético, ubicándose entre los valores definitivos que los fundamentan y las implicaciones normativas que generan, incluidas las instituciones y políticas que mejor representan y hacen efectivas dichas implicaciones. Por una parte, no debiéramos otorgar un papel fundacional a los derechos en el pensamiento ético: los derechos se derivan de nuestros intereses (algunos de ellos), que se pueden especificar independientemente del concepto de un derecho. Negar esta condición derivativa es el error que cometen los "fundamentalistas" de los derechos humanos como Nagel, quienes acaban envolviendo en misterio el procedimiento de identificación de los derechos humanos. Ahora bien, mi objeción al enfoque legal y al intervencionista es que cometen el error inverso: entienden los derechos de un modo excesivamente superficial, como algo que intrínsecamente implica un mandato de consagración legal o el establecimiento de remedios legales. En la actualidad, se vincula excesivamente a los derechos humanos no con categorías éticas fundamentales sino con instituciones y políticas específicas. En lugar de ser -como debieran- objeto de una evaluación 
potencial, a la luz de las exigencias de los derechos humanos, estas instituciones y políticas pasan a formar parte del significado mismo de tales derechos.

Un beneficio incidental de este distanciamiento conceptual de las condiciones de existencia de los derechos humanos respecto de las cuestiones relativas a su consagración legal y al intervencionismo es que permite desarrollar otra línea de respuesta a la crítica de "valores asiáticos" de los derechos humanos. En gran medida esa expresión refleja la angustia de que el reconocimiento de los derechos humanos inevitablemente conduzca a una cultura de tipo estadounidense, en la que, entre otras características, hay una Corte Suprema dedicada a la supervisión judicial, una población propensa al litigio y un debilitamiento de los vínculos comunitarios. Si enfocamos el reconocimiento de los derechos humanos como una cuestión de implementación en cuanto a cuáles diseños institucionales son más convenientes para realizarlos en un determinado contexto social, podemos aquietar parcialmente dichos temores mientras seguimos insistiendo en el respeto universal de los derechos humanos.

\section{Respuesta a la objeción relativa a la demandabilidad}

Onora $\mathrm{O}^{\prime}$ Neill introduce la objeción sobre la demandabilidad, contrastando los derechos universales de libertad y los derechos de asistencia social. Los primeros imponen deberes "negativos" que implican abstenerse de dañar a otros de múltiples maneras, mientras que los segundos supuestamente generan deberes "positivos" respecto del otorgamiento de bienes y servicios a sus titulares. Las disposiciones establecidas en los artículos 22 al 7 de la DUDH sobre los "derechos de asistencia social" son ejemplos de lo anterior, ya que incluyen los derechos a la seguridad social, el trabajo, el descanso y la recreación, junto con los derechos a un nivel de vida adecuado, educación y cultura. Éstos contrastan con los derechos tradicionales de "libertad", tales como los derechos a la seguridad física, la participación política, y la libertad de expresión y de religión. Sin embargo, la expresión "derechos de asistencia social" no está exenta de dificultades. En primer lugar, la intención no es sugerir que existe un derecho a la asistencia social propiamente tal sino solamente a ciertas condiciones que permitan Ilevar una buena vida. En segundo lugar, no necesariamente implica un compromiso respecto de un Estado de "bienestar" que garantiza bienes y servicios a sus ciudadanos mediante políticas de redistribución. Pueden existir otras formas institucionales -incluso mejores- de tales derechos, dependiendo de la sociedad de que se trate. Un contraste similar que se usa en este sentido, es aquél entre los derechos civiles y políticos de "primera generación" y los derechos socioeconómicos de "segunda generación". El orden temporal implícito quizás refleje la historia del reconocimiento legal de los derechos humanos, al menos en el contexto internacional, pero esto no debiera ocultar el respetable linaje de los derechos de subsistencia en el pensamiento occidental, incluyendo el pensamiento liberal y político.

Ahora bien, a diferencia de Geuss, $\mathrm{O}^{\prime} \mathrm{Neill}$ reconoce sin problemas que pueden existir derechos de ambos tipos, aunque no sean ejecutables - por diversas razones contingentes-en un momento o lugar determinados. Asimismo, para garantizar que sean exigibles, tanto los derechos de libertad como los de asistencia social normalmente requieren de la creación de instituciones que impongan deberes a ciertas personas y grupos para hacerlos valer. No obstante, $\mathrm{O}^{\prime} \mathrm{Neill}$ insiste en que hay una importante asimetría entre ambos tipos de derechos, una que implica que los derechos de asistencia social, a diferencia de las libertades, no pueden existir sin la presencia de algún mecanismo institucional que defina los deberes correlativos y los asigne a responsables pertinentes determinables, aunque no siempre se los pueda individualizar. La asimetría se refiere a la demandabilidad de ambos tipos de derechos: los derechos de libertad son eminentemente demandables aunque no existan instituciones competentes y una especificación de obligaciones 
correlativas, mientras que esto no rige para los derechos de asistencia social. Pero un derecho existe tan solo si se pueden reclamar los deberes que lleva aparejados. Por lo tanto, es una condición de la existencia de los derechos de asistencia social que haya instituciones que los sustenten y que, aunque no garanticen su realización, al menos definan y asignen los deberes respectivos:

La correspondencia entre los derechos universales de libertad y las obligaciones universales está relativamente bien definida, incluso cuando las instituciones pertinentes no existen o son débiles. Por ejemplo, la transgresión del derecho de no ser violada o de no ser sometida a tortura puede ser muy clara y quien la comete incluso puede ser identificable, aun cuando las instituciones encargadas de la observancia sean lastimosamente débiles. Pero la correspondencia entre el derecho universal a tener acceso a bienes y servicios y la obligación de proporcionar o entregarlos sigue siendo totalmente amorfa cuando las instituciones son inexistentes o débiles. Una mujer que no recibe sus derechos derivados de la maternidad puede, indiscutiblemente, afirmar que éstos han sido violados, pero a menos que las obligaciones de proporcionar dichos beneficios estén establecidas y asignadas, la mujer no sabrá a quién dirigirse para hacer valer su reclamo y sistemáticamente no se aclarará si hay algún "perpetrador" ni quien ha descuidado o violado sus derechos. ( $\mathrm{O}^{\prime}$ Neill 2000: 105; ver, también O’Neill 1996: 131-4)

Una inquietud que inmediatamente plantea este argumento es que depende de una supuesta distinción entre los derechos negativos de libertad y los derechos positivos de asistencia social, diferencia que el trabajo de Henry Shue nos ha enseñado a tratar con desconfianza ${ }^{22}$. Aunque partamos del supuesto de la existencia de una distinción significativa entre deberes negativos y deberes positivos, todos los derechos típicamente tendrán, como contraparte, deberes de ambos tipos. En consecuencia, algunas de las obligaciones más importantes que corresponden a los derechos universales de libertad son positivas. El derecho de no ser sometido a tortura generalmente impone deberes al Estado, por ejemplo, en cuanto a establecer y mantener una fuerza policial adecuada y un sistema judicial y penal, junto con otorgar poderes e imponer límites a los funcionarios de dichas instituciones para que respeten la integridad personal y, a su vez, prevenir $y$ castigar la violación de tal derecho por parte de otros. Asimismo, una implicación clave del HRP es el deber de no obstaculizar ciertas actividades que otros realizan para conseguir los medios para su subsistencia. Las causas significativas de la pobreza en muchos países en vías desarrollo incluyen, entre otras, los obstáculos sociales que impiden que las mujeres trabajen fuera del hogar. Evidentemente, este deber negativo tendría que ser complementado por deberes positivos para impedir esta interferencia y ayudar a quienes ya han sufrido a causa de su violación. Sin embargo, en este sentido, el HRP no difiere del derecho a no ser sometido a tortura.

El argumento de $\mathrm{O}^{\prime}$ Neill supuestamente es compatible con el pluralismo deóntico de los derechos. Tanto las libertades como los derechos de asistencia social generan deberes positivos. Pero al menos en el caso de los derechos universales de libertad, insiste $\mathrm{O}^{\prime} \mathrm{N}$ eill, sabemos quiénes son los principales responsables de la obligación primaria de la no interferencia: todos. En el caso de los derechos de asistencia social, sin embargo, no sabemos -a falta de un sistema institucional adecuado-quién tiene el deber de proporcionar los bienes y servicios pertinentes o cuál es el contenido preciso de dicho deber. De este modo, tales derechos se vuelven "radicalmente incompletos" y, en consecuencia, el proceso de su institucionalización no se limita a su observancia sino que afecta a su existencia misma:

\footnotetext{
22 Ver la discusión clásica en Shue (1996a: 35-64, 153-66). Dejaré de lado la objeción más profunda de Shue, a saber, que la distinción misma entre deberes positivos y negativos en lo referente a los derechos es excesivamente simplista y, en lo que sigue, reconoceré que hay alguna distinción viable que abarca a la gran mayoría de los casos.
} 
Si no hay claridad, en principio, respecto de dónde se deben interponer tales demandas, los llamamientos a supuestos derechos universales sobre bienes o servicios, incluida la asistencia social, son meramente retóricos y proclaman derechos "retóricos" ante terceros no especificados. ( $\mathrm{O}^{\prime}$ Neill 1996: 132)

¿Es suficiente este contraste para reivindicar la tesis de $\mathrm{O}^{\prime} \mathrm{Neill}$ de que la existencia de los derechos de bienestar social siempre depende de la institucionalidad? En mi opinión, no es así. Creo que O'Neill toma una diferencia de grado -relacionada con cuánto podemos saber, habitualmente, acerca de las obligaciones de la contraparte, independientemente del establecimiento de estructuras institucionales- y de manera ilegítima la convierte en una diferencia de categoría, a saber, que la existencia misma de los derechos de asistencia social es institucionalmente dependiente, mientras que los derechos relacionados con libertades no lo son. Asimismo, $\mathrm{O}^{\prime}$ Neill exagera el significado de nuestro conocimiento preinstitucional de los deberes asociados a derechos de libertad y sistemáticamente le resta importancia a lo que podemos saber acerca de las implicaciones deónticas de los derechos de asistencia social. Dicho de otro modo, cuando se trata de analizar los derechos de libertad, ella ve el vaso medio lleno, pero tratándose de los derechos de asistencia social, lo ve medio vacío.

El primer punto sale a la luz al considerar la importancia de los deberes positivos no asignados que tienen relación con derechos de libertad. El establecimiento de instituciones que lo sustenten y asignen deberes positivos es fundamental para la observancia del derecho de no ser sometido a tortura; ante la inexistencia de tales instituciones el hecho de que el derecho pueda ser demandable en contra de cada individuo tiene una importancia limitada. Pero, tratándose de la existencia de los derechos humanos, ¿por qué debiera impresionarnos tanto el deber negativo que es asignado preinstitucionalmente, a diferencia del no menos importante conjunto de deberes positivos para implementar y hacer cumplir ese derecho, que no lo es? Si bien, en principio, los violadores del derecho son identificables, este asunto no es trivial. La reflexión al respecto incluso nos puede llevar a concluir que la demandabilidad suele ser una precondición para poder hablar significativamente sobre violaciones de los deberes que implican los derechos humanos y, a su vez, hacer frente a cuestiones acerca del grado de culpabilidad y del castigo de este tipo de transgresiones. Pero una cosa son las condiciones que nos permiten determinar que hay violaciones de derechos humanos y otra cosa muy distinta es concluir que dichas condiciones deben servir de criterio para contestar la pregunta aparentemente previa e independiente de si un derecho humano existe o de si no ha sido satisfecho. La versión basada en los intereses que promueve la perspectiva estándar nos alienta a resistir la fusión de estas preguntas. Según dicha visión, un derecho humano existe si el interés individual universal es suficiente como para generar deberes que permitan promover y proteger dicho interés de diversas maneras. Pero quedará sin cumplirse si no se han garantizado los modos de promoción y protección a su titular, impidiéndole el acceso a lo que constituye el objeto de sus derechos. Estos son asuntos importantes, independientemente de cualquier preocupación relacionada con las violaciones de los derechos humanos y la posibilidad de identificar a los perpetradores.

Analicemos ahora la forma en que $\mathrm{O}^{\prime}$ Neill tiende a minimizar excesivamente lo que podemos saber acerca de los deberes generados por los derechos de asistencia social previo al establecimiento de un esquema institucional. El primer punto es que algunos de los deberes asociados con los derechos de asistencia social son en sí mismos asignados universalmente. En forma habitual, las obligaciones relacionadas con la entrega de los bienes y servicios pertinentes pueden permanecer sin asignar ni especificar hasta el momento en que se incorporan institucionalmente. No obstante, hay otro conjunto de deberes correlativos que, como reconoce $\mathrm{O}^{\prime}$ Neill, pueden constituir obligaciones impuestas universalmente (1996: 103). De modo que se podría pensar que todos tienen 
el deber de no obstruir -e incluso, quizás facilitar de algún modo, cuando el costo involucrado no es excesivo- el establecimiento de un marco institucional que permita especificar y asignar las obligaciones correlativas en cuanto a la provisión de bienes y servicios. También existen obligaciones de no privar a la gente de los recursos necesarios para mantenerse sobre la línea de la pobreza, las que se violarían, por ejemplo, si se cooperara activamente para conservar un orden económico internacional que posee el efecto previsible y evitable de empobrecer a la gente. Thomas Pogge argumenta enérgicamente que tales obligaciones son especialmente importantes en las actuales circunstancias mundiales.

La réplica de parte de O’Neill en este punto podría ser la siguiente. En el caso de los derechos de bienestar social, los deberes clave son los que implican proporcionar los bienes y servicios pertinentes y no los deberes negativos que significan evitar la imposición de un empobrecimiento grave ni los deberes derivados de ayudar a establecer las estructuras institucionales pertinentes. Estos deberes de suministro son los deberes primarios relacionados con los derechos de asistencia social, del mismo modo en que las formas adecuadas de no interferencia son un requisito de los deberes primarios asociados con los derechos de libertad. Así, el deber de abstenerse de empobrecer a otros es un deber negativo y, como tal, no puede ser el deber primario correlativo respecto del HRP, como generalmente se entiende dicho derecho. Hay otro deber secundario que es dependiente del deber primario. Consiste en promover y supervisar el cumplimiento de los deberes primarios por parte de los responsables primarios.

A la inversa de esta línea de argumentación, opino que debiéramos ser renuentes a reconocer que es posible identificar, haciendo abstracción de las circunstancias específicas, los deberes primarios asociados con cualquier derecho en particular. No es exagerado suponer, por ejemplo, que el HRP se podría garantizar adecuadamente para la gran mayoría de los ciudadanos de una sociedad rica y económicamente productiva que se caracterice por un conjunto de valores fuertemente identificados con los derechos humanos, mediante el reconocimiento generalizado y la observancia real de los deberes negativos de no privar a otros de la oportunidad de trabajar. Pero quizás debiéramos entender la invocación de los deberes "primarios" de otra manera. Se podría decir que los derechos de libertad pueden cumplirse plenamente en un mundo en el que todos cumplen con el deber negativo de la no interferencia. No obstante, esto no rige en el caso de los derechos de asistencia social. La posibilidad de que existan problemas de acción colectiva y desastres "naturales", por ejemplo, significa que también será necesario cumplir con deberes positivos de provisión para garantizar el disfrute de tales derechos. Sin embargo, incluso esta caracterización de primacía es problemática. Por ejemplo, el derecho a la libertad de expresión probablemente impone al Estado el deber de otorgar a sus ciudadanos la oportunidad de un mínimo nivel de alfabetización. El simple cumplimiento del deber "negativo" de no obstruir la libertad de expresión no bastará para cumplir con ese derecho. No obstante, reconozcamos, arguendo, que los deberes positivos de provisión tienen una prominencia especial en el caso de los derechos de asistencia social.

Sin embargo, en este caso la respuesta debiera ser que generalmente contamos con información suficiente como para saber que existen deberes que son correlativos con los derechos de asistencia social sin que el desempeño de dichos deberes sea demandable frente a terceros determinables. De este modo, conservamos la intuición esencial de que hay una correlación entre los derechos y los deberes, dejando de lado el requisito de que una condición de la existencia de los derechos es que sean demandables. ¿Cómo se puede fundamentar esta línea de pensamiento? Nuevamente la explicación de los derechos basada en los intereses ilustra adecuadamente el tema que nos ocupa. Esta teoría permite el conocimiento de la existencia de los derechos (y por tanto de la justificación de los deberes que corresponden a dichos derechos) sin que tales deberes deban ser 
especificados ni asignados con precisión a agentes determinados ${ }^{23}$. En cambio, la cuestión de la asignación y especificación es un tema adicional y no uno que requiere respuesta para poder establecer la existencia del derecho. Así, utilizando el HRP como ejemplo, si desarrollo más el argumento esbozado en la Sección I puedo saber que todos tienen el derecho de no padecer la pobreza extrema y que, por lo tanto, se justifica la imposición de deberes a terceros para garantizar tal condición. Esto se debe a que la importancia del interés es suficiente como para generar los deberes correlativos, dadas las limitaciones de las capacidades humanas, los recursos disponibles y las características generales de la vida en sociedad. Pero quiénes son las personas idóneas a las que se deben asignar dichos deberes es un tema aparte que requiere de mayor deliberación. En particular, implica reflexionar sobre cómo se asignan y especifican las obligaciones que surgen de un determinado derecho, y también qué obligaciones "por defecto" existen para los casos de quienes no cumplen con sus deberes ${ }^{24}$.

Cabe señalar que el planteamiento de estas cuestiones en el contexto de afirmar la existencia de derechos no proviene de incertidumbres sobre la posibilidad de que sea factible garantizar dichos derechos mediante la imposición de deberes. Si así fuera, la existencia misma de tales derechos sería dudosa, ya que los derechos fundamentan los deberes y los deberes deben cumplir con la condición de ser factibles (esta es la tercera objeción planteada en la Sección II). Por otra parte, una vez que hemos separado la demandabilidad como una cuestión diferente, podemos admitir que un derecho puede existir aunque la asignación y especificación de los deberes correlativos no se determine. El carácter indeterminado proviene del hecho de que se plantearán varios esquemas posibles para asignar y precisar con mayor definición los deberes correlativos. En el caso del HRP, la obligación primaria podría recaer en el Estado y, en otras circunstancias, en el grupo familiar, en una agencia internacional de ayuda contra la pobreza o en cualquier combinación de las anteriores. Cualquiera de estos esquemas puede ser aceptable en principio, pero cuál, si alguno, es el "mejor" dependerá de factores que son objeto de considerables variaciones locales y temporales. A menudo, no existirá una sola solución óptima sino varios esquemas irreductibles para la asignación y definición del HRP sin mayores diferencias substanciales entre sí. En efecto, O'Neill virtualmente reconoce este hecho al señalar que el derecho a los alimentos o al trabajo "puede satisfacerse de muchas maneras diferentes", por ejemplo al ganar dinero suficiente, tener acceso al uso de la tierra o mediante la pertenencia a grupos familiares o sociales determinados que se toman en serio la obligación de proporcionar el apoyo necesario. Pero luego afirma que "sin la existencia de una u otra estructura institucional determinada, estos supuestos derechos económicos son cuestiones retóricas más que derechos propiamente tales" (O'Neill 2000: 125). No obstante, hay dos razones para resistir esta austera conclusión.

La primera es el punto ad hominem de que incluso los deberes positivos de ayuda se pueden asignar independientemente de una estructura institucional, dado que los principios de responsabilidad pueden, en ocasiones, especificar adecuadamente quiénes son los responsables primarios pertinentes en determinadas circunstancias a través del razonamiento ético y sin mediar la colaboración institucional. Un ejemplo de ello son las situaciones de emergencia en las cuales algún agente está presente en calidad de espectador solitario, con la capacidad de tomar las medidas necesarias en forma mucho más eficiente que otro y a un costo insignificante. Otro ejemplo se da en el caso de las sociedades occidentales prósperas, donde las consideraciones relativas a la eficiencia, la rendición de cuentas y el valor de la autodeterminación política, entre otros factores, se juntan para generar una obligación pro tanto para los Estados con el fin de garantizar

\footnotetext{
23 Ver, por ejemplo, Raz (1986: 184).

24 Las obligaciones correlacionadas con el derecho de subsistencia son analizadas en Shue (1996a: 35-64, 153-66).
} 
que sus ciudadanos no caigan por debajo de la línea de pobreza. En sociedades afectadas por el fenómeno del "Estado débil", el deber primario radicaría en otro lugar ${ }^{25}$. Podemos reconocer que los casos que se acaban de mencionar apenas cubren todas las situaciones en las que la gente padece o se ve amenazada por la pobreza extrema. Por lo tanto, en su mayor parte, la asignación institucional de deberes se vuelve necesaria para una demandabilidad significativa. Una alternativa desagradable consiste en declarar un estado generalizado y permanente de "emergencia" en el que quizás todos los moradores de las sociedades occidentales acomodadas queden en posición de espectadores moralmente obligados.

Pero ahora entra al terreno la segunda respuesta. ¿Por qué debiera este carácter indeterminado -que, en todo caso, refleja la existencia de una pluralidad saludable de mecanismos para garantizar el derecho en lugar de la incertidumbre sobre la existencia de algún medio realista de proporcionarlo- socavar la existencia misma de tales derechos antes de su consagración institucional? ¿Por qué el interés de la persona y el hecho de que tal interés basta para generar a su respecto las obligaciones de respetar, proteger, y promover, etcétera, no debieran ser suficientes para justificar la existencia del derecho? En vista de la potencia del argumento a favor de reconocer e imponer deberes sobre la base de dicho interés, hay buenas razones para considerar el tema de la demandabilidad como independiente de la existencia de dicho derecho. Este tema es importante y amerita mayor investigación moral y empírica, negociaciones o una determinación formal en el contexto de la política democrática o del razonamiento judicial. Pero al abordar ese tema y tal como se puede demostrar por el tipo de argumentos esbozados en la Sección I, es necesario que el derecho exista antes de ser demandable.

La anterior línea de pensamiento se ve reforzada por una consideración adicional, a saber, que el carácter indeterminado de las implicaciones deónticas de un derecho no es sólo un relativo menoscabo a la idea de que los derechos de asistencia social existen en forma preinstitucional. Más bien, tiene relación con otra característica valiosa de los derechos, como el carácter "dinámico" de sus implicaciones normativas ${ }^{26}$. Los deberes generados por un derecho no se pueden determinar integralmente de una vez por todas; pueden variar gracias a la naturaleza de los agentes, las instituciones y los contextos sociales en cuestión. Para lograr una asignación y especificación adecuada de las obligaciones, es necesario recurrir a lo que Shue denomina "razonamiento estratégico" respecto de contextos específicos (Shue 1996a: 161). En segundo lugar, incluso dentro de un contexto particular, pueden existir una serie de maneras igualmente aceptables de asignar los deberes correlativos y especificar su contenido. La sensibilidad al contexto rara vez resultará en una única respuesta correcta frente al problema de la asignación y la especificación. Efectivamente, una función clave de la acción política democrática y del razonamiento legal consiste en proporcionar mecanismos legítimos para enfrentar aquello que no ha sido resuelto una vez que se han agotado los recursos de la razón natural.

Como consecuencia de lo dicho, una vez que uno justificadamente afirma la existencia de un derecho subsiste una indeterminación de las implicaciones normativas de tal derecho. Sin embargo, ello no plantea dificultades insuperables. Esto se debe a que lo que impulsa a la teoría de los derechos basada en el interés son precisamente los intereses que protege un derecho determinado, en lugar del conjunto específico de implicaciones normativas que genera. Esto último puede variar considerablemente dependiendo de los cambios en las condiciones sociales, y también puede

\footnotetext{
25 Ver Martha Nussbaum, quien considera que su teoría de la capacidad produce normas constitucionales que deben cumplir los Estados para garantizar que están dentro de los márgenes de la legitimidad. Para una crítica del punto de vista de que el Estado al que pertenece una persona es el principal responsable, ver Okin (2003: 295).

26 La descripción se deriva de Raz (1986: 186).
} 
admitir contrastantes especificaciones aun en condiciones similares, sin que el derecho deje de existir. Pero, al concebir los derechos de este modo tan versátil, pierde fuerza la tesis de que su misma existencia en un momento dado depende de una asignación específica de deberes. Lo que resulta vital para la existencia de los derechos es que los intereses que subyacen a ellos estén enraizados en obligaciones correlativas y no si se ha determinado una particular distribución o especificación de dichas obligaciones.

\section{Consecuencias del dinamismo de los derechos}

Cabe destacar dos consecuencias de este dinamismo. La primera es que ofrece una respuesta a la queja de Geuss en el sentido de que la forma en que habitualmente se perciben los derechos no sólo es una ficción (porque no son ejecutables), sino que, además, es una "ficción inconveniente". Geuss piensa que tal forma de percibirlos fomenta una cultura política esclerótica, obsesionada con la estabilidad de la titularidad de los derechos a expensas de la flexibilidad en cuanto a la adaptación a circunstancias cambiantes (Geuss 2001a: 147, 152, 154) ${ }^{27}$. Recurriendo a una metáfora de tipo notablemente Benthamita ${ }^{28}$, Geuss sostiene que los derechos garantizan que "la mano invisible del presente logre estrangular al futuro" (Geuss 2001a: 154). Ahora bien, resulta un poco extraño que Geuss parta por declarar que los derechos existen solamente si están respaldados por una asignación de deberes y mecanismos para su cumplimiento, para luego denunciar el anquilosamiento político que ello promueve. El reconocimiento del carácter "dinámico" de los derechos nos permite desmentir la acusación de conservadurismo precisamente al dejar en evidencia que la vinculación que Geuss hace entre los derechos y los mecanismos establecidos para su observancia es infundada. El mismísimo derecho puede variar considerablemente en cuanto a sus implicaciones normativas en distintas circunstancias y, además, se puede hacer cumplir de múltiples maneras diferentes. En una sociedad rural escasamente poblada, por ejemplo, las estructuras institucionales que garantizan el acceso al uso de la tierra pueden desempeñar un papel fundamental para garantizar el HRP. Sin embargo, gracias a la industrialización y al rápido crecimiento demográfico, el énfasis puede estar puesto en disponer de oportunidades de empleo adecuadas que beneficien a todos. El debido respeto de los derechos, por lo tanto, exige estar preparados para apoyar cambios radicales en las prácticas sociales e institucionales existentes. Las críticas de Geuss serían acertadas sólo si se dirigieran en contra de cierto exceso al que se presta el lenguaje de los derechos, a lo cual colabora su propia idea de identificar los derechos con los mecanismos efectivos para hacerlos valer. Pero dichas críticas no cuestionan (como él supone) el valor de los derechos en sí.

La segunda consecuencia del dinamismo, es más substancial y nos permite rechazar como falsa la opción entre la concepción interactiva y la institucional de los derechos humanos. Thomas Pogge, autor de esta diferencia, ha señalado:

Debiéramos concebir los derechos humanos principalmente como demandas planteadas a instituciones sociales coercitivas y en segundo lugar como demandas en contra de quienes respaldan tales instituciones. Esta visión institucional contrasta con la visión interactiva, que concibe a los derechos humanos como algo que somete el tratamiento de los seres humanos a ciertas limitaciones que no presuponen la existencia de instituciones sociales (...). Desde la visión interactiva de los derechos humanos, los gobiernos y las personas son responsables de no violar los derechos humanos. En

\footnotetext{
27 Esto coincide con la hipótesis nietzscheana de que el discurso de los derechos refleja los intereses de los débiles en un orden social estable y previsible. Ver Geuss (1997: 4).

28 Nota de los editores: de Jeremy Bentham.
} 
cambio, desde mi visión institucional la responsabilidad que ellos tienen consiste en trabajar a favor de un orden institucional y de una cultura pública que garanticen a todos los integrantes de una sociedad el acceso al objeto de sus derechos humanos. (Pogge 2002a: 46, 65).

Ambas explicaciones imponen restricciones conceptuales ex ante respecto de las implicaciones normativas de los derechos, apoderándose de asuntos que mejor se dejan al "razonamiento estratégico", que es sensible a los caprichos del tiempo y del lugar. Al hacerlo de este modo, se infringe el carácter dinámico de los derechos y, en términos más generales, se ilustran los peligros que implica sobrestimar la contribución que el análisis filosófico puede aportar a la deliberación política.

En consecuencia, se critica con razón la explicación interactiva debido a su ingenua suposición de que cada derecho directamente implica deberes correlativos respecto de ciertas personas o grupos específicos. En una versión minimalista de la explicación interactiva (como por ejemplo, el libertarianismo), todas las personas cargan con el deber negativo de no impedir directamente el acceso garantizado de los demás al objeto de su derecho. Una versión más maximalista (como el utilitarismo), impone deberes a los demás independientemente de su responsabilidad causal respecto de cualquier privación. Sin embargo, como ha argumentado Pogge, los deberes que se derivan de un derecho no pueden interpretarse de este modo solamente a partir del objeto del derecho. Para una sociedad determinada, la principal implicación normativa del derecho de no ser sometido a tratos degradantes, podría ser, por ejemplo, el deber de apoyar programas para mejorar el grado de alfabetización y los seguros de cesantía, garantizando que no sufran tales tratos un amplio sector de empleados domésticos (Pogge 2002b: 182). De este modo, la asignación y especificación de los deberes está mediada por la reflexión sobre las instituciones, las privaciones que ocasionan y las reformas que podrían impedir, mejorar y compensar tales penurias.

Pero el rechazo de la explicación interactiva no nos obliga a adoptar la concepción de su rival institucional. La primera explicación fue echada por tierra por la potencial complejidad (incluida la mediación institucional) que tiene el proceso de generación de implicaciones normativas a partir de los derechos humanos. Pero esto no establece forzosamente la presencia de un tipo específico de complejidad en cada caso. En particular, no implica necesariamente que los derechos humanos deban verse fundamentalmente como demandas formuladas a órdenes institucionales impuestos en forma coercitiva y, en segundo lugar, a quienes colaboran para mantenerlos. Exigir otra cosa equivale a imponer una restricción innecesaria a nuestro pensamiento estratégico acerca de las implicaciones deónticas de los derechos. Para que las inquietudes sobre los derechos humanos se activen en cualquier caso específico, ¿es realmente necesario identificar un orden institucional compartido que sea causalmente responsable de las privaciones pertinentes? Y, ¿será preciso que esas privaciones no hayan sido tomadas en cuenta por los "funcionarios" de dicho orden institucional, como insiste Pogge?

Inevitablemente, mucho depende de nuestra apreciación en cuanto a qué debiera considerarse como casos paradigmáticos de derechos humanos y de su violación. Pienso que un caso de esta índole podría ser el de una comunidad religiosa que ha buscado protegerse de la sociedad secular en un lugar remoto del interior de Australia. Esta comunidad, que ha sido autosuficiente durante décadas, mantiene contactos muy limitados con el mundo exterior. Si llegaran a fracasar sus cultivos en algún momento, exponiendo a sus miembros a un grave empobrecimiento que podría llevarlos a pasar hambre, ¿no es razonable pensar que el gobierno australiano violaría su deber de respetar los derechos humanos de la comunidad si no les proporciona la ayuda necesaria para subsistir, suponiendo que pudiera hacerlo a bajo costo? Dicho de otro modo, un deber positivo parece derivarse directamente del HRP y de diversos hechos relacionados con la posibilidad de proporcionar asistencia y con el costo que esto presume. Asimismo, las implicaciones contraintuitivas 
de la teoría institucional no se limitan a casos de deberes "positivos" correlativos a supuestos derechos humanos. Otro ejemplo, cuya condición paradigmática sería fuertemente impugnada por Pogge es el de un hombre que habitualmente comete graves actos de violencia en contra de su esposa e hijos. ¿Por qué se ha de negar que esté violando directamente los derechos humanos de sus familiares a la seguridad física? ¿Es razonable pensar que la dimensión de los derechos humanos solo corresponde en un caso así si su habitual conducta abusiva puede interpretarse como objeto de indiferencia oficial dentro de un esquema institucional impuesto de manera coercitiva? Incluso si este tipo de razonamiento institucional se puede llevar a cabo con éxito en casos intuitivamente convincentes como el recién descrito -y no hay nada que garantice que así será- su naturaleza precaria y sinuosa disminuye más que realza el poder crítico del discurso de los derechos humanos ${ }^{29}$. Esta evaluación se ve reforzada, quizás, por la admisión de Pogge de que pueden existir derechos morales universales, como el caso de violencia intrafamiliar descrito, que no son derechos humanos (2002b: 160). Supuestamente, tanto el derecho moral universal contra el maltrato físico como el derecho humano contra el maltrato físico se fundamentan en los mismos intereses humanos universales. En ese caso, ¿qué se gana con introducir un sistema bifurcado de derechos morales universales y por qué habría de reservarse el título de "derecho humano" para aquellos derechos morales universales que calzan con las especificaciones de la explicación institucional?

Ahora, podría plantearse la objeción de que la explicación institucional no es un obstáculo innecesario sino un potente ardid dialéctico en contra de quienes creen -como los partidarios del libertarianismo o de la tesis de O'Neill de la demandabilidad-que los derechos humanos (al menos en caso de falta de institucionalización) solamente generan deberes negativos. Pogge comparte dicha premisa con estos opositores. Conforme a su explicación, todos los seres humanos tienen el deber negativo de no respaldar instituciones sociales coercitivas que, pudiendo evitarlo, niegan a otros el acceso garantizado al objeto de sus derechos. Si están involucrados en una institución de este tipo, deben dejar de participar en ella o hacer algún tipo de reparación mediante actividades destinadas a lograr la reforma de la institución pertinente o la protección de sus víctimas (Pogge 2002a: 66). Sin embargo, es dudoso que cualquier ventaja dialéctica obtenida de este modo compense los costos incurridos.

Un tema de inquietud es que el ardid de Pogge parte concediendo demasiado, en la medida que ya hemos encontrado razones para resistir, por dogmática, la idea de que los derechos humanos implican exclusivamente obligaciones correlativas de tipo negativo. En segundo lugar, como demuestra el ejemplo de violencia intrafamiliar, al dar prioridad a la dimensión institucional, se puede afirmar que la explicación de Pogge no logra dar cuenta de los casos paradigmáticos de violación de los deberes negativos de abstenerse de hacer daño. Por último, no es para nada evidente que hacer esta concesión garantiza la victoria de la posición que se denomina a sí misma ad hominem. O'Neill podría llegar a responder, por ejemplo, que tratándose de la demandabilidad, la explicación institucional de los derechos de bienestar social sencillamente mueve la arruga de un lugar a otro de la alfombra. Porque, tal como reconoce Pogge, esa explicación implica la responsabilidad colectiva de todos los que participan en un orden institucional causante de

29 Thomas Pogge ha sugerido (comunicación personal) que el caso del lugar remoto en Australia está amparado por la explicación institucional, porque el gobierno de Australia reclama autoridad respecto del territorio australiano, incluida la parte habitada por esta comunidad imaginaria. Concedamos esta afirmación. Pero ¿qué sucede si modificamos el ejemplo y colocamos a la comunidad en una isla sin reclamar situada justo en el límite de las aguas territoriales de Australia, sin introducir cambios en los demás factores importantes? ¿Debiera este ligero cambio, potencialmente, hacer una diferencia substancial para determinar si el gobierno australiano tiene una obligación de prestar ayuda basada en los derechos humanos? La renuencia a aceptar que sí la tiene debiera provocar escepticismo (incluso en el caso del lugar remoto ) sobre la explicación de Pogge acerca de que existe una dimensión relacionada con los derechos humanos en un sentido más general. 
privaciones importantes (2002a: 64, 66). Pero es poco probable que O'Neill Ilegue a aceptar que una demandabilidad significativa de los derechos humanos se garantiza mediante la identificación de un grupo colectivamente responsable que potencialmente asciende a varios millones. En cambio, la verdadera demandabilidad requerirá de principios que distribuyan la responsabilidad al interior del grupo, especificando claramente qué debe hacer quién a modo de indemnización, reforma institucional, etcétera. Dichos principios reflejarán una gama diversa de consideraciones: los medios de los que disponen los individuos, su grado de contribución a y de beneficio por mantener instituciones dañinas, etcétera. Supuestamente, no hay una manera correcta (o, al menos, una sola manera evidente) de reflejar todas estas consideraciones en los principios de responsabilidad. El resultado ineludible pareciera ser que los principios que adjudican la responsabilidad requerirán, a su vez, de una formulación institucional. En consecuencia, la objeción de $\mathrm{O}^{\prime}$ Neill en cuanto a la demandabilidad persiste incluso en una lectura institucional del HRP: hasta que exista un orden institucional adecuado, el derecho no se podrá reclamar verdaderamente. Más aún, su objeción ahora se generaliza y abarca a todos los derechos humanos supuestos, no solamente los derechos de asistencia social, ya que los derechos de libertad también requerirán repartir la responsabilidad colectiva mediante mecanismos institucionales.

Evidentemente, la explicación institucional de Pogge merece una evaluación más amplia que la que se puede ofrecer en este trabajo. Pero se ha dicho suficiente como para plantear la inquietud de que Pogge injustificadamente extiende las poderosas técnicas que ha descrito para elevar las implicaciones normativas de los derechos humanos a la condición de limitaciones conceptuales respecto de la naturaleza misma de tales derechos.

\section{VI. ¿Poner a los derechos en primer lugar?}

Permítanme abordar un tema adicional planteado por O’Neill. Me refiero a su reiterada aserción de que los partidarios de los derechos humanos tienden a equivocarse al poner a los derechos "en primer lugar", cuando debiera darse prioridad a las obligaciones (o, al menos, debiéramos concebir los derechos y las obligaciones en una relación recíproca de figura y fondo ${ }^{30}\left(\mathrm{O}^{\prime} \mathrm{Neill}\right.$ 2002: 79-80; ver también O’Neill 1996: 140-1). En particular, se representa a los partidarios de los derechos de asistencia social como si dejaran de lado, livianamente, las cuestiones más difíciles sobre obligaciones correlativas. Asimismo, esta visión basada en los derechos no da cuenta adecuadamente de aquellos deberes que carecen de derechos correlativos, lo cual conduce a un concepto insuficiente de la moralidad, como si ésta se agotara en los principios de la justicia. Ahora bien, en buena medida, esta crítica puede ser apoyada por alguien que comparta la visión que yo he defendido. Pero necesitamos distinguir al menos tres significados diferentes que la noción de "prioridad" puede tener en este contexto.

En primer lugar, está claro que las obligaciones preceden conceptualmente a los derechos. Se puede tener una comprensión cabal del concepto de obligación, a saber una razón categórica con cierto grado de fuerza excluyente, sin lograr dominar el concepto de lo que es un derecho. En contraste, un derecho sólo puede dilucidarse haciendo referencia al concepto de obligación, debido a que los derechos se definen como los fundamentos de los deberes que les son correlativos. En segundo lugar, y en un plano más práctico, se plantea la cuestión de cuál es el tipo de retórica ético-política que resulta más efectivo para obtener cambios deseables en términos de actitudes y conductas. Me parece que, en este punto, O’Neill está plenamente justificada al reprender a

30 Nota de los editores: la expresión del texto original "figure and ground" se refiere a imágenes en las cuales se puede percibir, alternadamente, la figura como fondo o el fondo como figura. 
aquellos activistas de derechos humanos que proclaman todo tipo de derechos sin aparentemente considerar la justificabilidad, distribución o coherencia de los deberes relacionados. Esto demuestra que el discurso sobre los derechos es vulnerable al abuso. No obstante, otras formas del discurso moral también padecen de una vulnerabilidad similar, incluso aquellas que priorizan el lenguaje del deber ${ }^{31}$. Por otra parte, cuando consideramos los deberes correlacionados con los derechos humanos, bien podríamos descubrir (como sugiere Pogge) que existen considerables beneficios retóricos, frente a una audiencia occidental, si se enfatizan los deberes negativos de no dañar a otros en forma previsible y evitable. Sin embargo, en cuanto al orden de justificación, los derechos son anteriores a los deberes que fundamentan. Dicho de otro modo, algunos -aunque no todos los deberes- deben su existencia a sus respectivos derechos correlativos: estos deberes "perfectos" forman parte del campo de la justicia, que es una categoría ética, entre muchas otras. De este modo, los defensores de la perspectiva estándar pueden dar cabida a la existencia de deberes "imperfectos" que carecen de derechos correlativos -los deberes de caridad, clemencia, gratitud, etcétera- uniéndose así a O’Neill para condenar a los partidarios del libertarianismo y a otros que eliminan dichos deberes de nuestra perspectiva ética de la vida al considerar que los derechos son "la categoría ética fundamental" (O'Neill 1996: 143) ${ }^{32}$. Por otra parte, a pesar de que un derecho es anterior a la obligación que genera, sigue sin ser esencial en términos del orden de justificación. Ese lugar le pertenece al interés, al menos en la versión basada en los intereses de la perspectiva estándar que he propuesto. Por lo tanto, el propio interés de librarse de la pobreza extrema es el que constituye la base del HRP y es gracias a su existencia que se imponen deberes a los demás. El piso de la justificación es nuestra comprensión del bien. Evidentemente, esta última afirmación no ejercerá influencia sobre un kantiano, como O'Neill, que desea otorgarle autonomía "al derecho" o -más precisamente- a la esfera de lo deóntico, respecto de toda concepción sobre el bien ${ }^{33}$. Este último punto demuestra que mi argumento en contra de $\mathrm{O}^{\prime} \mathrm{Neill}$-e incluso de Geuss- dista de ser decisivo. El tema subyacente no tiene que ver con el carácter exigible ni con la demandabilidad sino que implica a los compromisos filosófico-morales más profundos de la persona. Tanto Geuss como O'Neill tienen serias dudas acerca de una explicación basada en el "bien" o el "interés" de los derechos humanos. En el caso de Geuss, éstas provienen de un escepticismo ético generalizado. Por contraste, $\mathrm{O}^{\prime}$ Neill se plantea importantes reservas sobre el concepto de un bien humano pluralista en este contexto: ¿ existe una concepción sólida del bien hacia la cual podamos converger en forma estable sin tener que pagar un precio metafísico exorbitante? Y, si la hubiera, ¿cómo se puede derivar un inventario de derechos a partir de esa concepción? ${ }^{34}$ Estas son cuestiones importantes, a las que uno debe responder mediante el desarrollo de una explicación de los derechos humanos basada en el bien y realizando una comparación con los esfuerzos desplegados por O'Neill para fundamentar los derechos en obligaciones perfectas derivadas mediante una prueba kantiana de universalización. ¿Acaso sería más convincente una justificación del derecho humano de no ser sometido a tortura, por ejemplo, sobre la base de que una política sobre la tortura no se pueda universalizar sin contradicciones? ¿ $\mathrm{O}$ se fortalecería el caso respecto de ese derecho al invocar directamente los intereses humanos fundamentales -autonomía, verse libre de dolor y degradación, etcétera- que están en juego? En cualquier consideración de este

31 Como O'Neill misma señala respecto del problema relativo a la "sobrecarga" de deberes que enfrenta el utilitarismo (2002: 78 n. 8).

32 Una descripción de cómo se podrían defender los deberes relacionados con la clemencia aparece en Tasioulas (2003).

33 Dos potentes manifestaciones de escepticismo acerca del lugar privilegiado del deber como parte integral del proyecto kantiano están expuestas en Williams (1985: Cap. 10) y Taylor (1995).

34 Del mismo modo en que una lista de compras no contiene en sí información sobre cuál adquisición debe tener prioridad respecto de las demás, la explicación pluralista de los bienes humanos no requiere en sí misma que algunos bienes sean respetados a expensas de los restantes. O’Neill (2002: 77). 
tipo es particularmente importante que la explicación de los derechos humanos basada en los intereses no necesariamente se vea subsumida -y por lo tanto no sea directamente susceptible- a los problemas que afectan a toda forma de consecuencialismo. Está de más decir que no actuaré como mediador entre las dos teorías en este escrito.

Una última observación, de carácter diagnóstico. En este trabajo he discutido y batallado contra el escepticismo acerca del HRP y la perspectiva estándar de dos filósofos, uno nietzscheano y una kantiana, respectivamente: me refiero a Geuss y $\mathrm{O}^{\prime} \mathrm{Neill}^{35}$. Se podría pensar que son aliados poco probables, dado que otros de sus compromisos difieren radicalmente. Pero desde la perspectiva del enfoque basado en los intereses frente a los derechos humanos, su convergencia no es sorprendente. Porque tanto la posición nietzscheana como la kantiana son recelosas de la idea del bien como se entiende este concepto en una visión básicamente aristotélica de la ética. Ellos, en cambio, le asignan prioridad, respectivamente, al poder de facto (de ahí su preocupación por la ejecutabilidad) y al deber (por consiguiente y de manera menos directa, de ahí su preocupación por la demandabilidad de deberes correlativos a derechos). Pero uno de los supuestos de este capítulo es que, para "poder completar el proyecto de la llustración" sobre los derechos humanos, en palabras de James Griffin (2001a: 2), necesitamos regresar más allá de la Ilustración a la tradición aristotélica de pensamiento sobre el bien humano y la especial protección que merece. En otras palabras, lo que habitualmente se considera la doctrina claramente "modernista" de los derechos humanos debe ser alimentada por raíces que son, en materia de historia intelectual, premodernas $^{36}$. Si regresamos a la idea del bien y si desarrollamos como teoría generadora de los derechos el que algunos de los intereses universales de las personas alcancen una trascendencia que justifique la imposición de deberes con el fin de protegerlos y respetarlos, entonces la ejecutabilidad y la demandabilidad -independientemente de su indudable relevancia práctica- dejarán de figurar entre las condiciones de existencia de los derechos humanos. Habrán sido desplazadas a un lugar importante, pero no fundacional en nuestro pensamiento sobre tales derechos.

\section{Conclusión}

Nuestro punto de partida fue la situación insatisfactoria del discurso contemporáneo sobre los derechos humanos. Es comprensible que los teóricos que aspiran a la claridad y el rigor rechacen instintivamente esta situación. Tampoco debe sorprender que propongan, como remedio, limitaciones conceptuales que amarran la identificación de los derechos humanos a varias consideraciones institucionales. Pero incluso las crisis auténticas pueden provocar respuestas desproporcionadas en que el "remedio" es peor que la enfermedad (o al menos peor que los remedios alternativos). Las teorías que se han criticado en el presente capítulo deben ser entendidas como reacciones exageradas de esta índole. Las innovaciones conceptuales que propugnan no pueden sustituir el sólido juicio ético y político en torno a los deberes que imponen los intereses humanos y las estructuras institucionales que mejor los encarnan.

\footnotetext{
35 Y es en la categoría kantiana, interpretada a grandes trazos, que podemos colocar a otros filósofos cuyos puntos de vista sobre los derechos se critican en este capítulo: Habermas, Rawls, y Pogge.

36 Esta comprensión de los derechos es la que Alasdair MacIntyre pasa por alto cuando -célebremente- descarta los derechos morales y, en particular, los derechos humanos como "ficciones morales": "La mejor razón para afirmar tan rotundamente que no existen tales derechos es precisamente del mismo tipo que la mejor razón que nos asiste para afirmar que las brujas no existen y que tampoco existen los unicornios: todos los esfuerzos por dar buenas razones para creer que tales derechos sí existen han fracasado. En la Declaración de los Derechos Humanos de Naciones Unidas de 1949 se sigue con gran rigor una práctica que a partir de entonces ha sido normal para la ONU: no dar buenas razones respecto de cualquier aserción" (1984: 60). Tal escepticismo me parece lamentable, en especial, porque el diagnóstico general sobre las deficiencias del enfoque ético kantiano y nietzscheano que fuera esbozado [por Maclntyre] en After Virtue es compatible en otros aspectos con las inquietudes de fondo que motivan mi argumento en este capítulo.
} 


\section{Bibliografía (en orden alfabético)}

Beitz, Charles (2004). "Human Rights and the Law of Peoples", in Chatterjee (2004). Marshall Cohen, Thomas Scanlon, and John A. Simmons (eds.) (1985). International Ethics. Princeton, NJ: Princeton University Press.

Feinberg, Joel (2003). "In Defense of Moral Rights", Problems at the Roots of Law: Essays in Legal and Political Theory. Oxford: Oxford University Press.

Geuss, Raymond (1997). "Nietzsche and Morality", European Journal of Philosophy, 5: 1-20.

Geuss, Raymond (2001a). History and Illusion in Politics. Cambridge: Cambridge University Press.

Geuss, Raymond (2001b). Public Goods, Private Goods. Princeton, NJ: Princeton University Press.

Geuss, Raymond (2003). "Outside Ethics", European Journal of Philosophy, 11: 29-53.

Griffin, James (2001a). "Discrepancies Between the Best Philosophical Account of Human Rights and the International Law of Human Rights", Proceedings of the Aristotelian Society Cl: 1-28.

Griffin, James (2001b). "First Steps in an Account of Human Rights", European Journal of Philosophy, 9: 306-27.

Habermas, Jurgen (2001). The Postnational Constellation: Political Essays. London: Polity Press.

James, Susan (2003). "Rights As Enforceable Claims", Proceedings of the Aristotelian Society, CIII: 133-47.

Maclntyre, Alasdair (1984). After Virtue: A Study in Moral Theory, 2nd edn. Notre Dame, IN: University of Notre Dame Press.

Nagel, Thomas (2002). "Personal Rights and Public Space", in Concealment and Exposure \& Other Essays. Oxford: Oxford University Press.

Nussbaum, Martha (2000). Women and Human Development. Cambridge: Cambridge University Press.

Okin, S. M. (2003). "Poverty,Well-being, and Gender:What Counts, Who's Heard?", Philosophy and Public Affairs, 31.

O’Neill, Onora (1989). Constructions of Reason: Explorations of Kant's Practical Philosophy. Cambridge: Cambridge University Press.

O’Neill. Onora (1989). Constructions of Reason: Explorations of Kant's Practical Philosophy. Cambridge: Cambridge University Press.

O’Neill, Onora (1996). Towards Justice and Virtue: A Constructive Account of Practical Reasoning. Cambridge: Cambridge University Press.

O’Neill, Onora (2000). Bounds of Justice. Cambridge: Cambridge University Press.

O’Neill, Onora (2002). Autonomy and Trust in Bioethics. Cambridge: Cambridge University Press.

Pogge, Thomas (2002a). World Poverty and Human Rights: Cosmopolitan Responsibilities and Reforms. Cambridge: Polity Press.

Pogge, Thomas (2002b). "Human Rights andHuman Responsibilities", in de Greiff and Cronin (2002). 
Rawls, John (1999b). The Law of Peoples: With "The Idea of Public Reason Revisited". Cambridge, MA: Harvard University Press.

Raz, Joseph (1986). The Morality of Freedom. Oxford: Oxford University Press.

Reddy, Sanjay and Thomas Pogge (2002). "How Not to Count the Poor! A Reply to Ravallion", www.socialanalysis.org.

Rorty, Richard (1993). "Human Rights, Rationality and Sentimentality", in Shute and Hurley (1993).

Rorty, Richard (1996). "Who Are We? Moral Universalism and Economic Triage", Diogenes, 173: 5-15.

Shue, Henry (1996a). Basic Rights: Subsistence, Affluence, and U.S. Foreign Policy, 2nd edn. Princeton, NJ: Princeton University Press.

Singer, Peter (2002). One World: The Ethics of Globalization. New Haven, CT: Yale University Press.

Tasioulas, John (2002a). "Human Rights, Universality and the Values of Personhood: Retracing Griffin's steps", European Journal of Philosophy, 10: 79-100.

Tasioulas, John (2002b). "From Utopia to Kazanistan: John Rawls and the Law of Peoples", Oxford Journal of Legal Studies, 22: 367-96.

Tasioulas, John (2003). "Mercy", Proceedings of the Aristotelian Society, CIII: 101-32.

Tasioulas, John (2005). "Global Justice without End?", Metaphilosophy, 36(1-2): 3-29.

Taylor, Charles (1995). "A Most Peculiar Institution", in J. E. J. Altham and Ross Harrison (eds.), World, Mind, and Ethics: Essays on the Ethical Philosophy of Bernard Williams. Cambridge: Cambridge University Press.

Taylor, Charles (2004). Modern Social Imaginaries. Durham and London: Duke University Press.

Waldron, Jeremy (1993b). Liberal Rights. Cambridge: Cambridge University Press.

Williams, Bernard (1985). Ethics and the Limits of Philosophy. London: Fontana. 